\title{
Vertical profiles, optical and microphysical properties of Saharan dust layers determined by a ship-borne lidar
}

\author{
F. Immler and O. Schrems \\ Alfred Wegener Institute for Polar and Marine Research, Bremerhaven, Germany \\ Received: 15 January 2003 - Published in Atmos. Chem. Phys. Discuss.: 21 May 2003 \\ Revised: 19 July 2003 - Accepted: 25 August 2003 - Published: 15 September 2003
}

\begin{abstract}
A unique data set of ship-borne lidar measurements of Saharan dust layers above the Atlantic ocean has been collected aboard the research vessel Polarstern with a mobile Aerosol Raman Lidar (MARL) during the LIMPIDOcampaign in June 2000. Extended Saharan dust layers have been observed in the region between $8.5^{\circ} \mathrm{N}$ and $34^{\circ} \mathrm{N}$ in an altitude range between 2 and $6 \mathrm{~km}$. The continental, North African origin of the probed air masses is confirmed by 8day backward trajectories. The Saharan dust is characterized by an optical depth in the range of 0.1 and 0.3 , a depolarization around $10 \%$ and high lidar ratios of $45 \mathrm{sr}$ at $532 \mathrm{~nm}$ and $75 \mathrm{sr}$ at $355 \mathrm{~nm}$. The backscattering by the dust particles at the UV-wavelength is relatively weak, resulting in a negative color index. From the measured optical properties the effective radius and the refractive index of the dust particles are derived using a new approach based on Mie Theory and nonspherical scattering calculations. The low backscatter coefficient observed at $355 \mathrm{~nm}$ is due to significant absorption which increases with decreasing wavelength. This finding agrees very well with results from satellite and sun photometer measurements. The effective radii decrease from about $3 \mu \mathrm{m}$ at the base to $0.6 \mu \mathrm{m}$ at the top of the dust plumes. The non-spherical shapes of the dust particles are responsible for the high values of the lidar ratios.
\end{abstract}

\section{Introduction}

The presence of Saharan dust layers in the equatorial NorthAtlantic region far from the coast was already observed by Charles Darwin in 1832. Nowadays, satellite images reveal that extended regions of the Atlantic are frequently covered with dust which originates from the arid regions of Africa and is present all year round but with a significant maximum

Correspondence to: F. Immler

(fimmler@awi-bremerhaven.de) in summer (Herman et al., 1997; Husar et al., 1997). The Saharan dust travels thousands of kilometers with the trade winds, transporting estimated 100-400 Mtons of minerals westward to the Caribbean (Prospero et al., 1996). In fact, all the upper soil in the Caribbean stems from Africa. Saharan dust not only has an important impact on the coastal and tropical ecosystems of central America by supplying mineral nutrients for algae and plants but also by importing fungi and bacteria (Griffin et al., 2001).

Tegen et al. (1996) report that $50 \pm 20 \%$ of the mineral dust comes from soils that are disturbed by human activities. This anthropogenic change in atmospheric composition leads to significant impacts on the biosphere (Shinn, 2000) and it also has an important influence on the atmosphere itself. Possibly, anthropogenic increase of soil dust emission may be another contribution to manmade climate change (IPCC, 2001). Dust particles reflect and absorb radiation and they may serve as cloud nuclei. Additionally, they may have an impact on atmospheric photochemistry by supplying the surface for heterogeneous reactions and influence for instance the ozone budget (Hanisch and Crowley, 2002). Thus, this type of tropospheric aerosol plays an important role in the heat balance of the atmospheric system. Alpert et al. (1998) report that dust may lead to regional heating rates of up to $6 \mathrm{~K} /$ day. Yet, there are still great uncertainties as to assessments of the radiative impact of mineral aerosol due to the high variability of the temporal and spatial distribution. The magnitude and even the sign of the radiative forcing is still uncertain, but anthropogenic dust forcing may be comparable to that of other anthropogenic aerosols like sulfate (Sokolik and Toon, 1996).

The effect of aerosol to climate forcing depends strongly on the aerosol properties, such as its vertical distribution and moisture content as well as the properties of the aerosol in the underlying boundary layer and the presence of clouds (Hsu et al., 2000). Most of these parameters cannot be measured by satellite borne instruments. Lidars offer the opportunity to 
measure these atmospheric properties with high vertical and temporal resolution and are therefore an important tool to determine the radiative impact of Saharan dust. In addition, ships provide a mobile platform in oceans allowing to cover extended geographical regions. The data which we present here give detailed information on the aerosol's vertical distribution and relative humidity profiles. We also demonstrate the possibility of retrieving microphysical properties of Saharan dust from lidar data.

The measurements presented here were performed aboard the German research vessel "Polarstern" during the cruise ANT XVII/4 from Punta Arenas/Chile to Bremerhaven/Germany where we observed extended layers of dust in an altitude from around 2 to $4-6 \mathrm{~km}$ on two occasions. The lidar measurements provide profiles of the backscatter coefficient and depolarization at two wavelengths $(355 \mathrm{~nm}$ and $532 \mathrm{~nm}$ ), as well as an estimate of the optical depth. The water vapor was measured by the Raman technique. Additionally, two daily radiosonde launches provided temperature, humidity and wind profiles. One of the two also measured ozone using an EEC sonde.

The interpretation of the data in terms of the microphysical properties of the dust particles requires the knowledge of the complex refractive index $n$ of the aerosol along with other assumptions that we need to make. Recently, a climatology of aerosol properties retrieved from a global network of sun-photometers (AERONET) was reported (Holben et al., 2001; Dubovik et al., 2002). Another study which retrieves the imaginary part of $n$ from satellite data (Colarco et al., 2002) gave very similar results. Thus, the properties of Saharan dust are allocated to a level that allows us to establish a specific retrieval of microphysical parameters of the Saharan dust using our lidar data. This retrieval is based upon spherical and non-spherical scattering theory.

\section{Instrumentation and data analysis}

Lidar measurements were performed aboard the German research vessel Polarstern during a cruise from Punta Arenas/Chile $\left(53^{\circ} \mathrm{S}\right)$ to Bremerhaven/Germany $\left(53^{\circ} \mathrm{N}\right)$ from 6 May to 16 June 2000 ("LIMPIDO-campaign"). The Mobile Aerosol Raman Lidar (MARL) uses a Nd:Yag-Laser with $250 \mathrm{~mJ}$ Pulse generation at both $532 \mathrm{~nm}$ and $355 \mathrm{~nm}$ at $30 \mathrm{~Hz}$ repetition rate. The backscattered light is detected by means of a $1.1 \mathrm{~m}$ Cassegrain telescope with a field of view (FOV) of $0.5 \mathrm{mrad}$. The light signals are then passed to a 8-channel polychromator by optical fiber after it has been separated by its polarization. Also, the inelastic Raman backscatter from $\mathrm{N}_{2}$ at $607 \mathrm{~nm}$ and $387 \mathrm{~nm}$ and by $\mathrm{H}_{2} \mathrm{O}$ at $407 \mathrm{~nm}$ are detected. The following subsections give a brief description of the methods used to retrieve aerosol parameters from the lidar measurements.

\subsection{The background aerosol backscatter ratio}

The tropospheric aerosol in the altitude range from about $7.5 \mathrm{~km}$ to $12 \mathrm{~km}$ is primarily investigated because it serves as an input parameter for further lidar signal inversions. The mean aerosol extinction coefficient $\alpha_{0}$ in the upper troposphere can be determined directly from the Raman Lidar signals (Ansmann et al., 1992). The extinction at the elastic wavelength can then be estimated using a power law type wavelength dependence of the extinction coefficient:

$\alpha(\lambda)=\alpha\left(\lambda_{0}\right)\left(\frac{\lambda}{\lambda_{0}}\right)^{A}$.

For the so called Ångström coefficient A we use the value $1.3 \pm 0.5$ in the case of the background aerosol in this study. Its content is expressed in terms of the backscatter ratio defined as

$R(z)=\frac{\beta_{e l}^{A}+\beta_{e l}^{M}}{\beta_{e l}^{M}}$,

where $\beta_{e l}^{M}$ and $\beta_{e l}^{A}$ are the backscatter coefficients for molecular and aerosol scattering, respectively. The backscatter ratio expresses a mixing ratio of aerosol with $R=1$ referring to an aerosol free case. The backscatter ratio of the background aerosol $R_{0}$ is estimated from the extinction assuming a constant lidar ratio $S$, i.e. the ratio of extinction to backscatter coefficients, of $44 \pm 5$ and $46 \pm 5 \mathrm{sr}$ at $532 \mathrm{~nm}$ and $355 \mathrm{~nm}$, respectively:

$R_{0}=\alpha_{0} /\left(S \overline{\beta^{M}}\right)+1$,

where $\overline{\beta^{M}}$ is the mean value of the molecular backscatter coefficient over the range which is under consideration.

Figure 1 shows the results based on the evaluation of 60000 shot averages (about $40 \mathrm{~min}$ ) during night time for each data point. Data containing clouds in the upper tropospheric region are filtered out. The error bars give a sum of statistical and systematic errors. The latter arise from the uncertainties of S and A as mentioned above. Generally the background aerosol in the tropics turns out to be slightly higher than at the midlatitudes. A clear north-south difference could not be detected. South of $25^{\circ} \mathrm{S}$ we find a mean value of $1.06 \pm 0.03$ while north of $25^{\circ} \mathrm{N}$ we get $1.08 \pm 0.05$. The mean value in between is $1.09 \pm 0.03$ at $355 \mathrm{~nm}$. The background backscatter ratios at $532 \mathrm{~nm}$ can be calculated either the same way or it can be inferred from that at $355 \mathrm{~nm}$ using a law equivalent to Eq. (3) for the backscatter coefficient. We found that the latter method yields smaller errors with $1.18 \pm 0.10,1.27 \pm 0.08$ and $1.21 \pm 0.18$ in southern, tropical and northern latitudes, respectively. Generally the background aerosol loading is found to be rather low with a high variability, especially in the midlatitudes. 


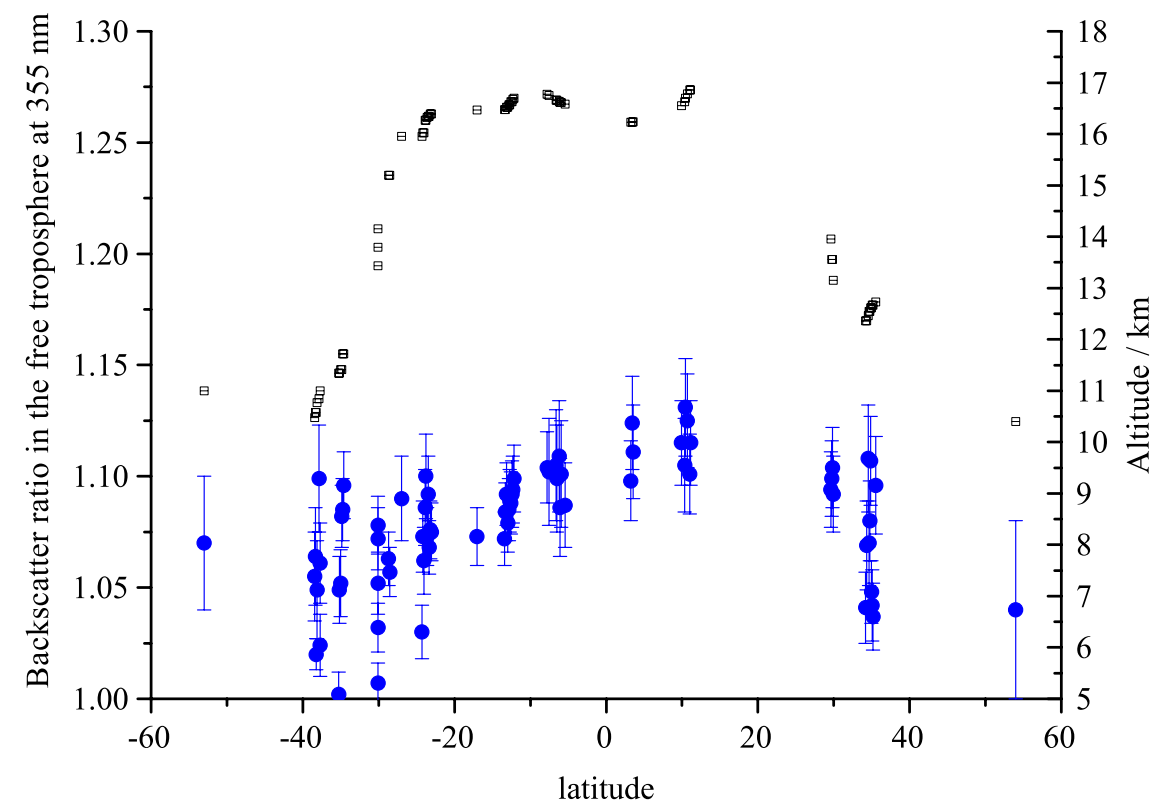

Fig. 1. Backscatter ratio of the tropospheric background aerosol at $355 \mathrm{~nm}$ (dots) and tropopause altitude (squares) versus latitude.

\subsection{The backscatter ratio of the dust layer}

The MARL system is primarily designed and operated to measure cirrus clouds and stratospheric aerosols. The setup of the system, in particular the big primary telescope mirror, creates a range with a non-unity geometric overlap between laser beam and the telescope-FOV that reaches up to about 4 $\mathrm{km}$. Standard elastic backscatter inversion procedures - like the Klett-method Klett (1985) - fail within this range due to the generally unknown geometric overlap factor. However, the backscatter ratio can be determined by assuming that this factor is equal at all altitudes of the elastic and the $\mathrm{N}_{2}$-Raman signal. $R(z)$ can then be calculated from the lidar signals by

$R(z)=C \frac{P_{e l}(z)}{P_{N_{2}}(z)}$

where $P_{e l}(z)$ and $P_{N_{2}}(z)$ are the measured elastic and Raman signals, $\mathrm{r}$ espectively. $\mathrm{C}$ is a constant which is determined at the upper troposphere at the altitude $z_{0}$ where $R\left(z_{0}\right)=R_{0}$. An additional correction is applied that accounts for the different absorption due to the wavelength shift between the elastic and inelastic scattered light (Ansmann et al., 1992). This way we are able to retrieve aerosol backscatter profiles for the troposphere starting at an altitude of $300 \mathrm{~m}$.

Since our system detects the elastic backscattered light separated by its plane of polarization we have to use the equation

$$
P_{e l}(z)=P_{e l}^{\|}(z)+C^{\prime} \delta_{M} P_{e l}^{\perp}(z)
$$

to calculate the total or "unpolarized" lidar return. Here $P_{e l}^{\|}(z)$ and $P_{e l}^{\perp}(z)$ are the measured parallel and perpendic- ular polarized signals, respectively. $C^{\prime}$ is a constant that is again determined in an aerosol free region such that

$\delta\left(z_{0}\right)=\frac{\delta_{M} C^{\prime} P_{e l}^{\perp}\left(z_{0}\right)}{P_{e l}^{\|}\left(z_{0}\right)}=\delta_{M}$.

$\delta_{M}$ is the molecular depolarization which is assumed to equal 0.014 (Beyerle et al., 1998). Besides the random noise, systematic errors arise from the necessary assumptions made, namely the boundary condition $R_{0}$ and the molecular depolarization $\delta_{M}$. Even at night time random noise in the Raman channel leads to statistical uncertainties in $R(z)$ of about 0.1 at $532 \mathrm{~nm}$ and 0.02 for $355 \mathrm{~nm}$ and is therefore about as important as the systematic error.

\subsection{Depolarization}

The volume depolarization profile can be calculated according to Eq. (6). The particle depolarization, which expresses the depolarization created by the particles only, is calculated by

$$
\delta_{P}(z) \doteq \frac{\beta_{A}^{\perp}}{\beta_{A}^{\|}}=\frac{\left(R_{e l}^{\perp}-1\right) \delta_{M}}{R_{e l}^{\|}-1} .
$$

The parallel and perpendicular backscatter ratios $R_{e l}^{\perp}$ and $R_{e l}^{\perp}$ are determined according to Eq. (4). Since the backscatter ratio is needed to calculate the particle depolarization, one main error source is again the uncertainty in $R_{0}$. This means, that if the parallel backscatter ratio drops below 1.10 (at $532 \mathrm{~nm}$ ) the standard deviation becomes large and the particle depolarization can no longer be determined. Another 


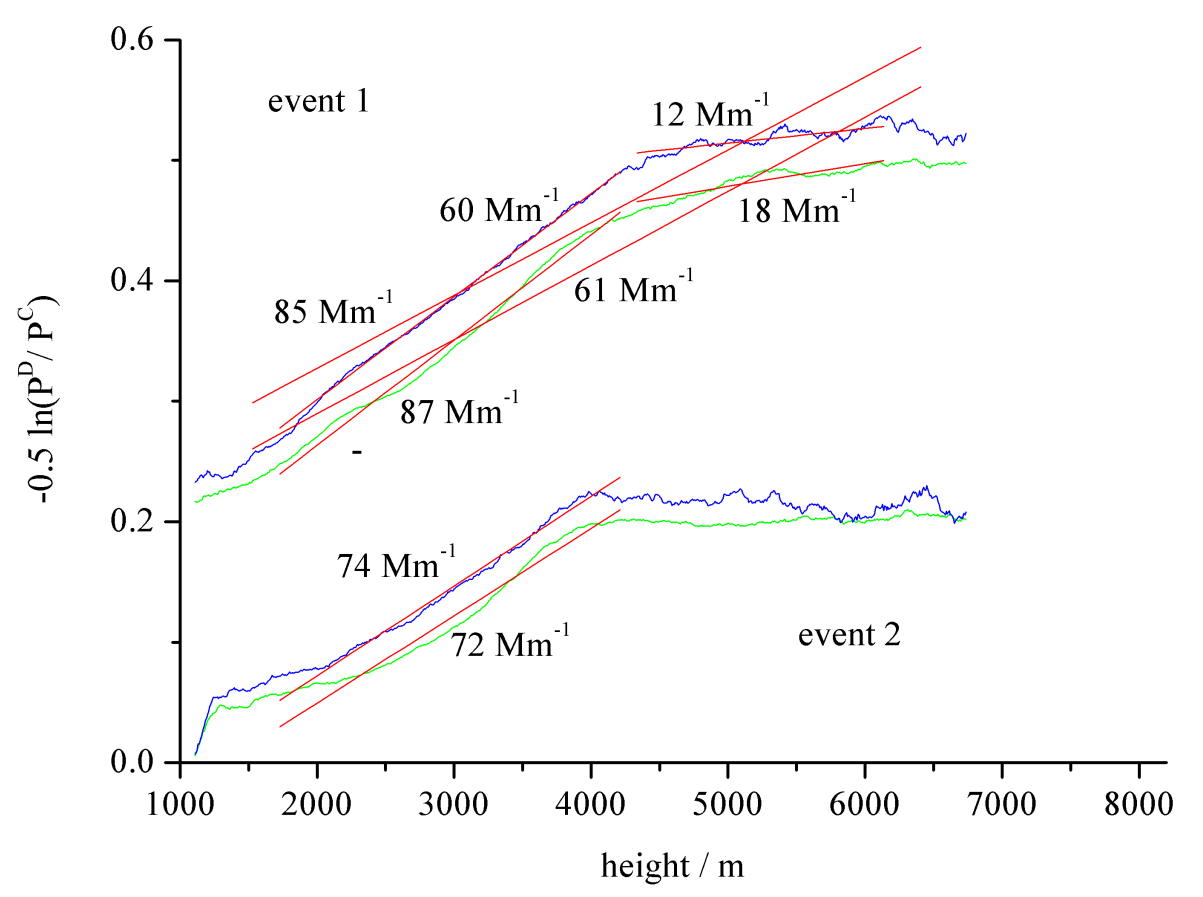

Fig. 2. Retrieval of the extinction coefficients of the Saharan dust clouds by determining the slope of the ratio of two Raman profiles. Extinction in the lower layer of event 1 (upper curves) are higher than the overall mean. For further details see Sect. 2.5 of the text.

important error source is the assumption made for $\delta_{M}$ which depends on instrumental constraints, namely the bandwidth of the filters. Additionally, the overall system depolarization should be taken into account (Biele et al., 2000). However, the simplified procedure which we use here leads to very reasonable results, not only in so far as the dust aerosol is concerned but also cirrus are described appropriately (Immler and Schrems, 2002). It should be kept in mind that considerable bias might be connected to the depolarization measurement. The estimated relative error is in the order of $25 \%$.

\subsection{Relative humidity}

Detection of the inelastic backscatter from $\mathrm{H}_{2} \mathrm{O}$ at $407 \mathrm{~nm}$ allows the determination of the water vapor mixing ratio (wvmr) as suggested by Melfi (1972).

$$
\begin{gathered}
\operatorname{wvmr}(z)=C^{\prime \prime} \frac{P_{\mathrm{H}_{2} \mathrm{O}}}{P_{e l}} \exp \left[\int_{0}^{z} \alpha_{\mathrm{H}_{2} \mathrm{O}}^{M}\left(z^{\prime}\right)-\alpha_{e l}^{M}\left(z^{\prime}\right)+\right. \\
\left.\alpha_{\mathrm{H}_{2} \mathrm{O}}^{A}\left(z^{\prime}\right)-\alpha_{e l}^{A}\left(z^{\prime}\right) d z^{\prime}\right] .
\end{gathered}
$$

For determining the calibration factor $C$ " the results are compared with radiosonde data which were launched twice a day from Polarstern. C" proved to be reasonably constant during the campaign.

The relative humidity is calculated using the water vapor mixing ratio measured by the lidar and the temperature and pressure profiles provided from the sondes. Therefore weighted mean profiles from the next available sondes were created. Since there are often considerable temporal and spatial displacements between the two measurements (up to $12 \mathrm{~h}$ and some $500 \mathrm{~km}$, respectively) appreciable uncertainties must be taken into account regarding these data.

\subsection{Estimation of the aerosol optical depth (AOD)}

The optical depth is calculated by integrating the extinction coefficient profile $\alpha(z)$ over the range where the cloud appears. Unfortunately, a retrieval of $\alpha(z)$ from the backscatter profile in this case is not feasible since this would require a reasonably good knowledge of the extinction to backscatter ratio S. This can not be assured. Mattis etal. (2002) measured an unexpectedly large lidar ratio in a Saharan dust plume over Germany between 50 and $80 \mathrm{sr}$ at $532 \mathrm{~nm}$, while Mie theory suggest a much smaller number. In effect, the lidar ratio of dust plumes remains very uncertain. Also, from our measurements we can not retrieve $\alpha(z)$ directly from the Raman signals using the method suggested by Ansmann et al. (1990) since the lidar signals in the range of the dust clouds are not free of geometric compression.

To account for this problem we divide a Raman signal that was measured when a dust plume was present $P_{N_{2}}^{D}(z)$ by a temporally close signal that was measured when no dust was observed $P_{N_{2}}^{C}(z)$. Since the lidar system was very stable and did not need realignment during the period of consideration the geometric compression function is assumed constant and 
Table 1. Saharan dust events observed during the cruise ANT XVII/4 of the research vessel Polarstern in 2000

\begin{tabular}{|c|c|c|c|c|c|c|}
\hline \multirow[t]{2}{*}{ Event } & \multicolumn{2}{|c|}{ time (UT, dd.m, hh) } & \multirow{2}{*}{$\begin{array}{l}\text { latitude } \\
{ }^{\circ} \mathrm{N}\end{array}$} & \multirow{2}{*}{$\begin{array}{l}\text { long. } \\
{ }^{\circ} \mathrm{W}\end{array}$} & \multirow{2}{*}{$\begin{array}{l}\text { base } \\
(\mathrm{km})\end{array}$} & \multirow{2}{*}{$\begin{array}{c}\text { top } \\
(\mathrm{km})\end{array}$} \\
\hline & start & end & & & & \\
\hline 1 & $2.6,19$ & 3.6 , & 8.5 & 22 & 2.0 & 6.0 \\
\hline 2 & $6.6,20$ & $7.6,22$ & 29 to 34 & 22 & 2.0 & 4.2 \\
\hline
\end{tabular}

thus cancels. Ignoring changes in the atmospheric density profile, the extinction profile can then be calculated by

$\alpha(z) \simeq-\frac{1}{2} \frac{d}{d z} \ln \left[\frac{P_{N_{2}}^{D}(z)}{P_{N_{2}}^{C}(z)}\right]$.

This procedure is depicted in Fig. 2 for the two events observed. It shows the ratio of 30 min averaged Raman signals taken at different times. The upper curves show the Raman signal at $387 \mathrm{~nm}$ (blue) and $607 \mathrm{~nm}$ (green) taken on 6 June at 23:00 UTC divided by the last profile taken before the plume arrived on the same day at 00:30 UTC. The lower curves refer to event two and show the ratio of 30-min average profiles taken on 6 June 21:00 UTC and 7 June 23:00 UTC. The straight lines represent the derivatives which are calculated by a linear regression and the results are given within the graph.

\subsection{The color index}

The microphysical properties of the dust particles become apparent in the depolarization and the wavelength dependence of the backscatter coefficient. The latter is expressed in terms of the color index c, which is defined as

$c(z)=-\ln \left(\beta_{A}^{\lambda_{1}}(z) / \beta_{A}^{\lambda_{2}}(z)\right) / \ln \left(\lambda_{1} / \lambda_{2}\right)$

If a wavelength dependence of the backscatter coefficient equivalent to Eq. (1) is assumed, the index would be independent of the actual wavelength used. It should be kept in mind, that this is generally not the case. The color index is the equivalent to the Angström coefficient of the extinction (Eq. 1), but these values are generally not equal.

\section{Results}

Two Saharan dust events have been observed from $8.5^{\circ} \mathrm{N}$ to $13^{\circ} \mathrm{N}$ and $29^{\circ} \mathrm{N}$ to $34^{\circ} \mathrm{N}$ along $22^{\circ} \mathrm{W}$. The first observation was made just after sunset on 2 June and the dust plume persisted the whole night. During the next day, no measurements were carried out, but since a layer of very similar appearance was again measured in the evening of 3 June it is likely, that the plume had persisted throughout the day. We therefore summarize these observations and refer to them as event 1 (Table 1).
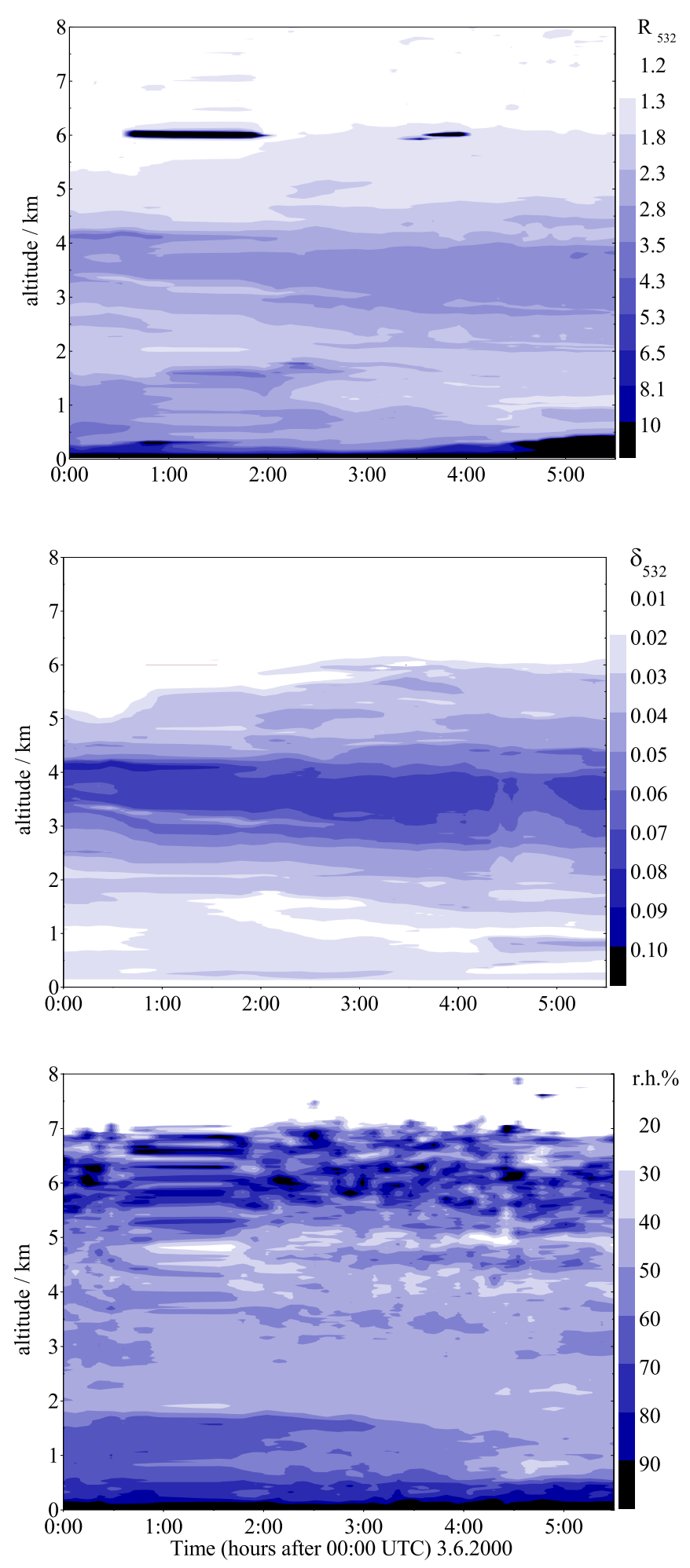

Fig. 3. Backscatter ratio (upper) and volume depolarization (middle panel) at $532 \mathrm{~nm}$ as well as relative humidity measured by the Raman lidar (lower panel) on 3 June 2000 around $10^{\circ} \mathrm{N} 22^{\circ} \mathrm{W}$. The Saharan dust layer extends from $2 \mathrm{~km}$ up to $6 \mathrm{~km}$. 

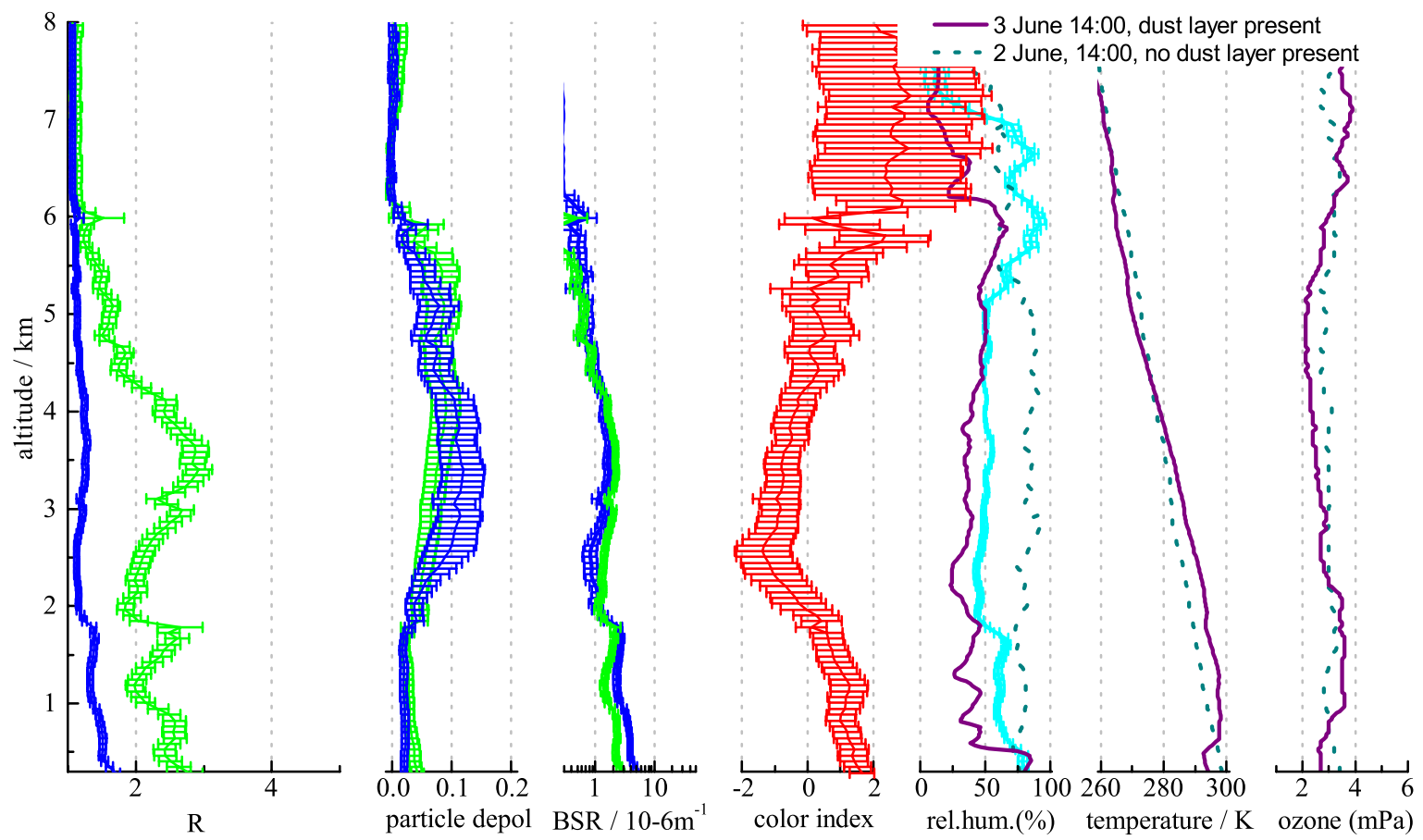

Fig. 4. Profiles of the backscatter ratios, the particle depolarization and the backscatter coefficient at $532 \mathrm{~nm}$ (green) and $355 \mathrm{~nm}$ (blue) of event 1 based on 120000 shot (ĩ.2 hours) averaged lidar data taken on 3 June around 2:00 UTC. Also, the color index profile and the relative humidity measured by the lidar is plotted (cyan). Profiles of the relative humidity, the temperature and the ozone concentration from temporally closest radiosonde measurements are added: indicated in dotted lines are profiles measured at a time when according to our observation most likely no dust layer was present, while the purple lines show data of a radiosonde that went through the dust layer. Indicated in dotted lines are the profiles measured at a time when, according to our observations, most likely no dust layer was present. The purple lines show data of a radiosonde that went through the dust layer.

This first event appeard just north of the intertropical convergence zone (ITCZ) and is shown in Fig. 3a to Fig. 3c. The dust plume is separated into a stronger lower and weaker upper part. In the lower part, $\alpha$ is with approximately $80 \mathrm{Mm}^{-1}$ much higher than in the upper one with around $15 \mathrm{Mm}^{-1}$ (Fig. 2). This corresponds with the measured backscatter ratio which reaches up to 4 in the lower part of the plume, but hardly reaches 1.5 in the upper part. Moreover, we find that the lower part is rather dry with relative humidity around $50 \%$, while in the vicinity of the layers top the relative humidity exceeds $80 \%$. Occasionally thin clouds form on the top edge of this layer.

The dust plumes base is marked by a minimum of $\mathrm{R}$ at about $2 \mathrm{~km}$ (Fig. 3). Below this altitude, in the planetary boundary layer (PBL), $\mathrm{R}$ increases again to rather high values of 4 and above. A significant difference in the properties of the maritime aerosol in the PBL and the dust layer above becomes apparent when considering the depolarization in Fig. 3b. The aerosol below this minimum in the PBL shows basically zero depolarization while the Saharan dust is depolarizing with about $10 \%$. From the profiles shown in the upper panel of Fig. 4 it can be seen that the color ratio stays around 0 in the boundary layer while it takes negative values in the dust layer above. The significant differences of these optical properties between the maritime aerosol and the dust layer allows a clear distinction of the two aerosol types (Sasano and Browell, 1989).

The optical depth of the dust layer, estimated with the procedure explained above, varies between 0.2 and 0.3 . It is therefore lower than that of the PBL which reaches values as high as 0.8 at 3 June, 07:00 UTC (estimated using a lidar ratio of 40 (Barnaba and Gobbi, 2001)), but also shows high variations, e.g. it nearly vanishes around 02:30 UTC (Fig. 3). However, the PBL generally supplies most of the atmosphere's AOD during the dust event. This is still true when taking into account that during the whole period tropical cirrus were present in the tropopause region, since their optical depth was only about 0.03 (Immler and Schrems, 2002b).

After passing through a period without dust occurrences, about $2000 \mathrm{~km}$ north of the first Saharan dust encounter, at around $30^{\circ} \mathrm{N}$ a second event was detected in the night from 6-7 June. In analogy to the first event,no measurements were performed during the following day, but when they were 

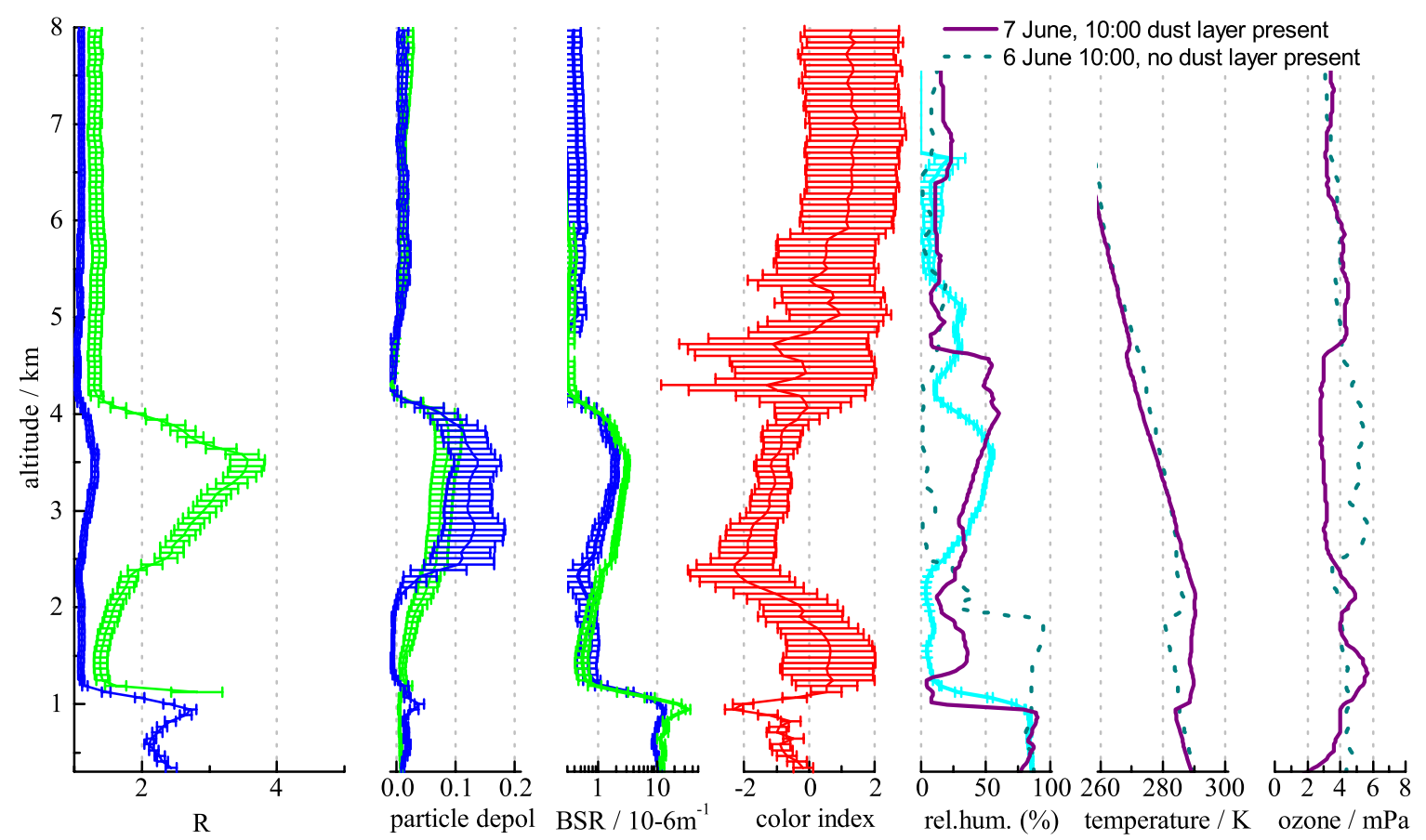

Fig. 5. Same as Fig. 4 for the second event event. This lidar profiles were taken on 6 June 2000 at 23:00 UTC at about $30^{\circ}$ N.

Table 2. Optical and microphysical properties of the Saharan dust layers, the latter are retrieved based on Mie-calculations with (without) a correction for the shape effect. The first two rows give the mean values across the entire dust plumes profile of a selected 40 min average of each event. The column "Max. R" shows the range of variance of the backscatter ratio during the whole event. To show the differences the mean values were calculated separately for the upper and lower part of the plume. The results are shown in the lower two columns

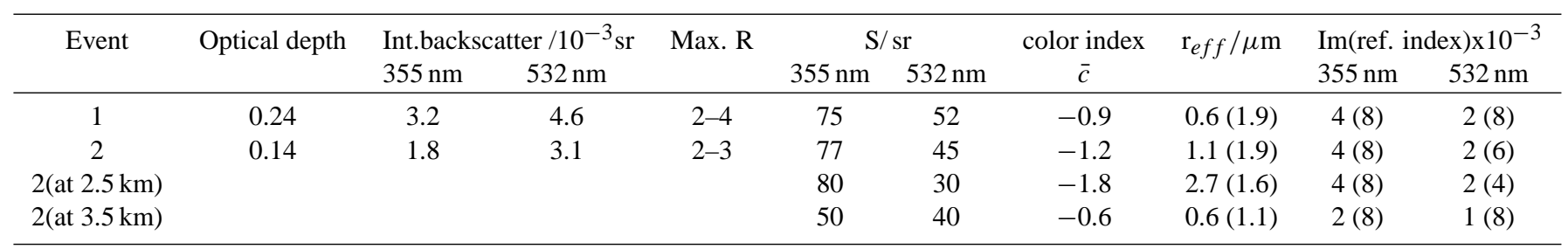

resumed in the next night, a dust plume was observed with a backscatter, a depolarisation, and a relative humidity profile very similar to the ones measured the night before. We therefore assume it belongs to the same event which presumably has persisted throughout the day.

Some more features of this second, "subtropical" event were very similar to those of the previous, "tropical" dust plume, for instance the elevated altitude range it appeared in. This suggests that both dust layers are made of the same type of aerosol, however, there were also some significant differences. The more northern "subtropical" layer of event 2 only reached an altitude of about $4 \mathrm{~km}$, while its "tropical" counterpart extended up to $6 \mathrm{~km}$. Also, the optical depth of the second event was somewhat lower (see Table 2). Furthermore, the two layers appeared in very different surroundings.
From the relative humidity profile in Fig. 4 measured with the Raman lidar, it can be seen, that the humidity within the dust layer in both cases is about $50 \%$. This coincidence is contrasted by the very different moisture content of the air above and below the dust layers. While the "tropical" dust plume is embedded in rather humid air (r.h. $>70 \%$ ), the "subtropical" layer is surrounded by very dry airmasses (r.h. <30\%).

On the other hand, the profiles shown in Fig. 4 make the similarities between the two events apparent which clearly indicate that the observed plumes consist of the same type of particles. Both dust layers exhibit a depolarization of about $10 \%$ and show a negative color index. Also, an increase of the color index with increasing altitude is observed in both cases. The lidar ratios retrieved with the procedure explained in the previous section show very similar values and 
a significant wavelength-dependence in all cases (Table 2). The optical properties measured by the MARL strongly suggest, that both events are consisting of the same type of aerosol, namely Saharan dust.

It is worth noticing, that a comparison of ozone profiles measured during and outside the dust events (Fig. 4 right panel) suggests that ozone is depleted in the Saharan air mass. This is particularly the case in event 2 , when the ozone was measured in the morning ( $3.5 \mathrm{~h}$ after sunrise). This might be connected with the influence of dust on the photochemical cycle in the troposphere (Zhang et al., 1994; Hanisch and Crowley, 2002).

\subsection{Backward trajectories}

To clarify the origin of the observed aerosol layers, backward trajectories were analyzed. We used the service provided by the British Atmospheric Data Center (BADC) to retrieve trajectories based on ECMWF reanalysis data. Figure 6 shows the results. Clearly, every time the dust layer was observed the air originated from the Sahara, while dust free air came from the tropical areas of Africa or the north-west Atlantic. The right panels in Fig. 6 show the altitude (in terms of pressure) of the air parcel as a function of time with yet again the red line representing the dust layer. Assuming, that the dust was taken up when the air was inside the PBL, i.e. the pressure was higher than $900 \mathrm{hPa}$ one may estimate the age of the layers to be about 7 and 3 days for event 1 and 2, respectively.

There is no evidence from the trajectories, that the faint upper and the thicker and less humid lower part of event 1 have different origins. It remains questionable how the rather high humidity in the uppermost part of this layer can be explained. Possibly, the humid airmass from above is mixing with the dust layer triggering the formation of the clouds that were detected by the lidar at the top edge of the Saharan dust layer (Fig. 3).

Event 2 gives an example of an intrusion of a subtropical air mass into midlatitude air. The dust layer around $3 \mathrm{~km}$ seems to be the only part of the column that has the arid continental origin. It is embedded in midlatitude air that had descended from higher altitudes, what explains its dryness. The different properties of the air surrounding the dust layers reported in the previous section are thus very nicely reflected in the back-trajectory analysis.

\subsection{Microphysical properties}

We have already pointed out, that the depolarization and color index of the dust differs significantly from that of the PBL-aerosol. Both dust events show a depolarization around $10 \%$, indicating a similar composition of the aerosol. In contrast the aerosol in the PBL depolarizes only very weakly with $1-3 \%$ (Fig. 4). Also, the color index is negative in the case of the dust and around zero or above in the PBL. Obviously, these two parameters contain information about mi- crophysical properties of the aerosol. Another parameter that depends on the particle properties is the lidar ratio. We found it to be quite high and strongly wavelength dependent for the Saharan dust cases, similar to other lidar measurements of Saharan dust (Mattis et al., 2002).

For the interpretation of the optical behavior of the aerosol measured by lidar, an appropriate scattering theory is required. Mie's theory Mie (1908) describes the scattering of light from spherical particles. Since one result of this exercise is zero depolarization, we can conclude, that the dust particles are not spherical and that Mie theory is not appropriate. However, due to the lack of a better applicable theory, we use Mie's theory in the first place to explain the wavelength and size dependence of the scattering and discuss nonspherical effects later in this section.

One important input parameter is the complex refractive index $\left(n=n^{\prime}+i k\right)$. Dubovik et al. (2002) reported that desert dust exhibits a pronounced absorption in the blue spectral range. For dust plumes measured on Cap Verde they find $k=0.0025$ at $440 \mathrm{~nm}$ and $k=0.0007$ at $670 \mathrm{~nm}$. The reported value by Colarco et al. (2002) of $k=0.004$ at $360 \mathrm{~nm}$ agrees very well with Dubovik's results when the latter are extrapolated into the UV-region. To investigate the influence of these findings on the lidar measurements, we have calculated the color index and the lidar ratio as a function of the effective radius $r_{e f f}$, assuming a lognormal size distribution using Mie's theory. Figure 7 shows the results for two cases, the first uses the refractive indices suggested by Dubovik et al. (2002) interpolated to the lidar wavelengths $(n=1.53+i * 0.004 / n=1.52+i * 0.002)$ at $355 / 532 \mathrm{~nm})$, the second uses the same real but a zero imaginary part (dotted lines). The effect of the UV absorption is most pronounced for aerosols with $r_{e f f}>1 \mu \mathrm{m}$. At both wavelengths the lidar ratio increases with $r_{\text {eff }}$ to values above $50 \mathrm{sr}$, while it remains around 10 in the non-absorbing case. At $532 \mathrm{~nm}$ this increase is not so pronounced. The dependence of the absorption on the wavelength causes the color index to become strongly negative for $r_{e f f}>1 \mu \mathrm{m}$, while it remains around 0 for a non-absorbing aerosol.

Qualitatively, our measurements aboard Polarstern agree well with the results of Mie theory. The outstanding features of the Saharan dust, i.e. the high and wavelength dependent lidar ratio and the negative color index appear to be consequences of the absorbing properties in the blue and UV region. Additionally, the increasing tendency of the color index with increasing altitude suggest that particle sizes decrease with altitude. This makes sense if sedimentation is considered an important process that could produce to such a size dependency on altitude. However, the agreement between our lidar results and climatology of Dubovik et al. (2002) based on photometer measurements may be due to the fact that both inversion algorithms are based on Mie Theory. It is therefore important to dicuss the influence of the evident asphericity of the particles on the retrievals. 

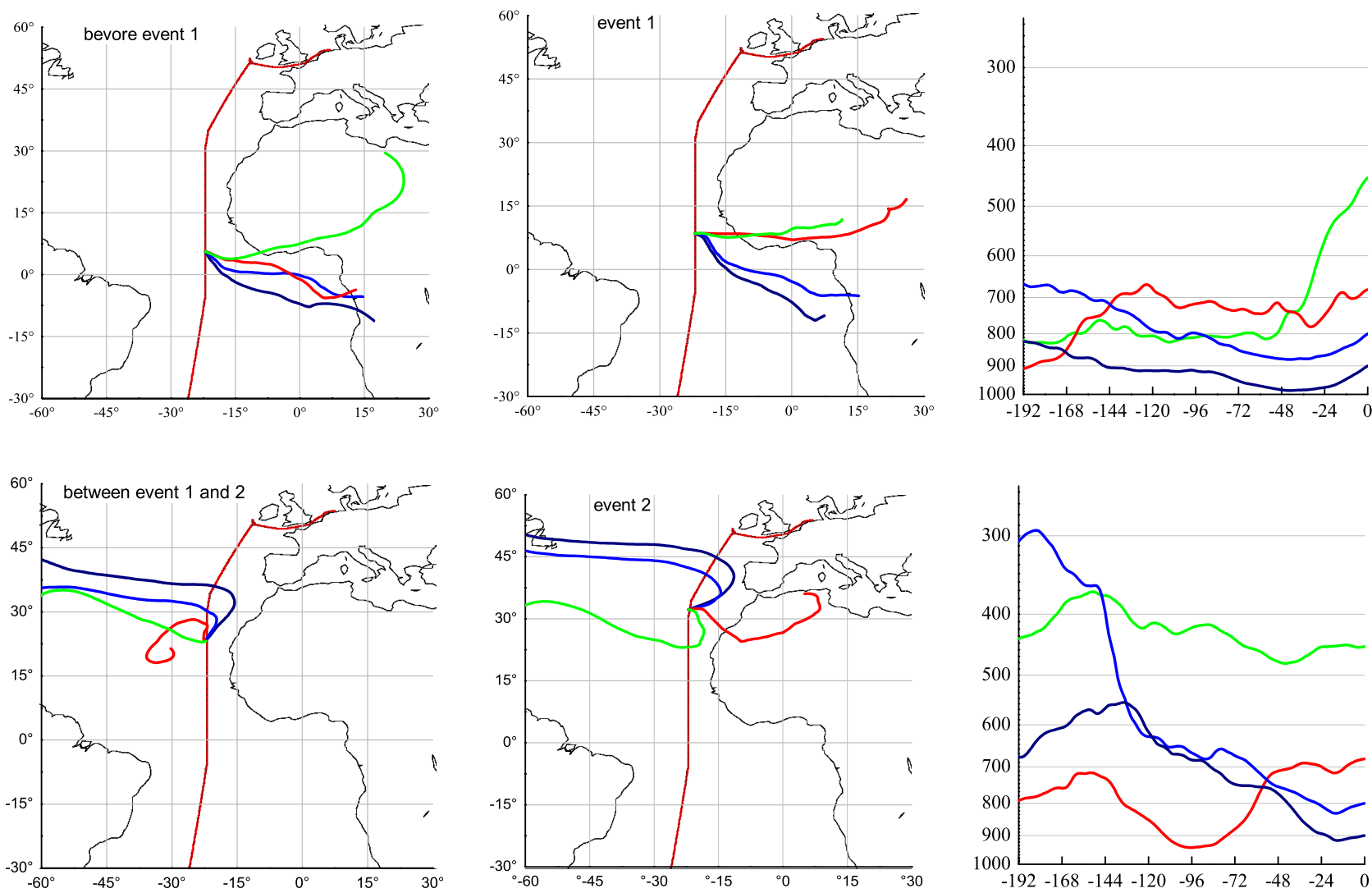

Fig. 6. 8-day backward trajectories of air masses sampled during the Polarstern cruise. The panels on the left show trajectories of air masses free of dust (2 June, 06:00 UTC and 5 June, 12:00 UTC). The panels in the middle correspond to the Saharan dust event 1 (upper) and event 2 (lower panel, June, 12:00 UTC). The panels on the right give the pressure level (hPa) as a function of time. The red lines represent the layer, where the dust has occurred $(3.2 \mathrm{~km})$, the blue lines are from lower layers $(0.9$ and $1.9 \mathrm{~km})$, the green line represents a higher layer $6.5 \mathrm{~km}$. The dark red line shows the route of "Polarstern".

One of the basic differences between photometer and lidar measurements of aerosols is that the photometer measures forward scattering, while the lidar is based on the backscattering. Mishchenko et al. (1997) showed on the basis of extensive T-matrix calculations for dust-like aerosol that the differences of the scattering phase function between Mie and non-spherical particles are small in the forward scattering direction, while they are largest in the backward direction. Therefore the non-sphericity is expected to cause only small errors in the inversion of photometer data, but it will have a significant impact on lidar data. In particular the lidar ratio is greatly affected by the non-sphericity. According to Mishchenko et al. (1997) the lidar ratio of an ensemble of randomly oriented spheroids is 1.5 to 3 times higher compared to that of surface equivalent spheres. On the other hand the effect of the shape does not seem to affect the color index significantly. This does not imply that the backscatter itself is not affected, but that the asphericity affects it equally strong for different wavelengths. If $\beta$ is changed by the same factor at $355 \mathrm{~nm}$ and $532 \mathrm{~nm}$, the color index c remains unchanged according to Eq. (10). Mishchenko et al. (1997) showed, that this is in good approximation the case for effective size parameters $>6$. This corresponds at $532 \mathrm{~nm}$ to an effective radius of $0.5 \mu \mathrm{m}$. The aerosol we are looking at presumably meets this requirement.

On this basis we have tried to retrieve the microphysical properties of the Saharan dust. Therefore a database was set up which contains the results of Mie calculation for dust aerosol. We used a bimodal lognormal size distribution defined by:

$N(r)=\sum_{x=1}^{2} \frac{N^{i}}{2 \pi \log \sigma^{i}} \exp \left(-\frac{\left(r-r_{m e d}^{i}\right)^{2}}{2 \log ^{2} \sigma^{i}}\right)$,

where the accumulation mode is fixed to $r_{\text {med }}^{0}=0.05$, $\log \sigma^{0}=0.24$ and $N^{0}=650 \mathrm{~cm}^{-3}$ (Dubovik et al., 2002). The median radius of the coarse mode $r_{m e d}^{1}$ is varying from about $0.1 \mu \mathrm{m}$ to $3 \mu \mathrm{m}$. The second independent variable is the refractive index which is also open within some limits. We used the ones most frequently reported in the literature: 


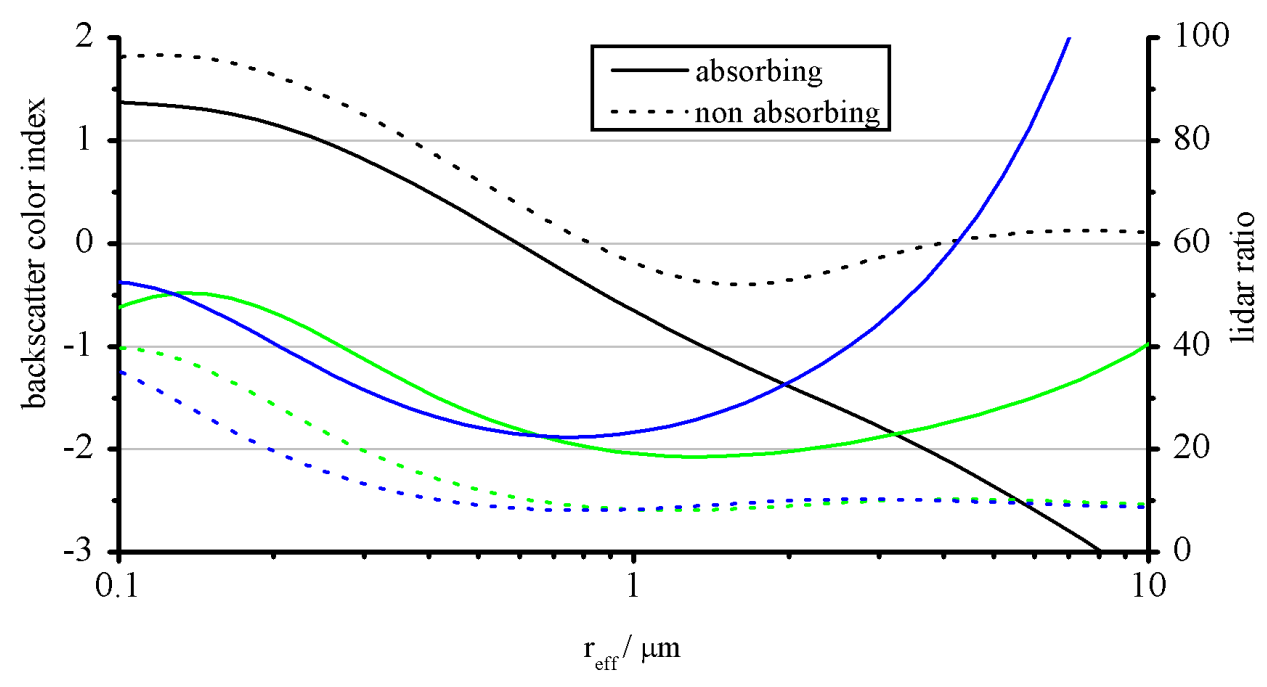

Fig. 7. Behavior of the color index (black) and the lidar ratio (blue for $355 \mathrm{~nm}$, green at $355 \mathrm{~nm}$ ) according to Mie calculation using the refractive indices given by Dubovik et al. (2002). For comparison the dotted lines give the same quantities for refractive indices with an imaginary part $k=0$.

the Cap Verde type (Dubovik et al., 2002), a non-absorbing "Quartz-like" type (Sokolik and Toon, 1999), the 'dust-like' type given by D'Almeida et al. (1991) and some intermediate values to give a total of 8 different indices. With these parameters we have calculated the optical properties using Mie theory. This database is scanned to find the aerosol type that best matches our data by minimizing the function:

$\zeta^{2}=\sum\left(\frac{M^{i}-M_{\text {model }}^{i}}{\Delta M^{i}}\right)^{2}$.

$M^{i}$ and $M_{\text {model }}^{i}$ are the measured and modeled optical parameters (lidar ratios and the color index), respectively. This procedure allows us to determine an aerosol type with optical properties that best match our measurement. It is characterized by the refractive index and the effective radius defined by:

$r_{e f f}=\frac{\int r^{3} N(r) d r}{\int r^{2} N(r) d r}$.

In a first run we use the lidar ratio as calculated by Mie theory and in a second run an asphericity correction is applied to the lidar ratios as it is suggested by Mishchenko et al. (1997). The results are given along with the measured values in Table 2, the numbers in brackets give the values of the best fits without the correction for the aspherical effect.

Generally, in all cases we have investigated, the "Cap Verde"-type refractive index is the best match to our data with $\zeta$ only few percent, when applying the aspherical correction. If this correction is not applied, higher values of the imaginary part can compensate the shape effect to some extent as was already pointed out by Menzies et al. (2002). But these fits show lower correlation coefficients with $\zeta$ around $30 \%$. Due to the rather high errors in our measurement we cannot exclude this possibility. However, it seems much more likely, that the dust we have measured shows an intermediate imaginary part of the refractive index, increasing in the UV. These results agree very well with those reported by Dubovik et al. (2002) and Colarco et al. (2002).

Also, the effective radii we have retrieved are very plausible: the younger dust layer of event 2 contains with $r_{e f f}=1.1 \mu \mathrm{m}$ larger particles in mean than the aged dust observed during event 1 . This sedimentation effect is also reflected in the vertical distribution of the effective radius. Since particles with radii above $1 \mu \mathrm{m}$ sink with about $100 \mathrm{~m} / \mathrm{d}$ we expect the upper part of the plume to be depleted of this mode while the coarse particles may still be present in the lower part. This agrees very well with our finding for event 2 with $r_{e f f}$ below $1 \mu \mathrm{m}$ in the upper and about $3 \mu \mathrm{m}$ in the lower part .

\section{Conclusions}

During the cruise ANT XVII/4 of the research vessel Polarstern we observed two events of Saharan dust with a multiwavelength Raman lidar. The first was encountered just north of the ITCZ, in a period where tropical cirrus were present at high altitudes. The second layer was detected around $30^{\circ} \mathrm{N}$ in the subtropics. The two events differed significantly as far as their vertical profile, optical depth and other macrophysical properties were concerned. The first event was surrounded by tropical air, which was more humid than the Saharan air mass, leading to occasional formation of thin clouds 
at the top of the layer. The subtropical plume on the contrary was embedded in very dry midlatitude air. In both cases the underlying planetary boundary layer contained a variable amount of sea salt aerosol with an optical depth that sometimes exceeded that of the Saharan dust layer. This emphasized the value of vertically resolved measurements of tropospheric aerosol. Column measurements provided for instance by photometers may in such a case be difficult to interpret, since by principle the presence of different layers and their vertical extent can not be deduced from that data.

The extinction, the lidar ratio and the color index of the Saharan dust measured by the lidar were comparatively stable and they were also very similar among the two observed events. As a consequence this also applied to the microphysical properties, namely the effective radius and the refractive indices as far as we could retrieve them from these measurements. We found that the effective radius of the dust particles was about $3 \mu \mathrm{m}$ at the base of the plume and lower than $1 \mu \mathrm{m}$ at the top. In all cases refractive indices of $1.53+i * 0.004$, $1.52+i * 0.002$ at $355,532 \mathrm{~nm}$ best matched our data. These results are in very good agreement with climatological data of Saharan dust retrieved from ground-based photometer measurement (Dubovik et al., 2002) as well as with properties deduced from satellite measurement (Colarco et al., 2002). The discussion of our results in the context of spherical and aspherical scattering theory leads us to the conclusion, that the high lidar ratios of Saharan dust that were observed in this and other studies (Mattis et al., 2002) are primarily due to the aspherical shape of the particles. On the other hand, the color indices seems not to be so much affect by the particles' shape. Its negative value is a consequence of the increasing absorption at the smaller wavelength. Using a correction function calculated by Mishchenko et al. (1997) for the lidar ratio of aspheric aerosols, we can explain the unusual optical behavior of the dust aerosol consistently.

The spectral behavior may be attributed to the optical properties of clay minerals like kaolinite and most importantly of hematite, which strongly absorbs in the blue and UV-A. (Sokolik and Toon, 1999). Different optical properties observed in other regions like in the Pacific (Menzies et al., 2002) or North America (Ferrare et al., 2001) by lidar may have been due to different sizes and different composition of the material. This suggests, that in principle lidars should be able to distinguish the composition and hence the origin of certain dust plumes. Extinction measurements based on Raman scattering in the UV and the visible spectral region are certainly compulsory for this task.

We have shown that the vertical structure as well as the optical and microphysical parameters of Saharan dust can be determined from ship-borne measurements in the Atlantic. These important parameters may help to determine the impact of Saharan dust on the regional and global radiation budget which is yet uncertain.
Acknowledgements. We are grateful to I. Beninga and W. Ruhe (Impres $\mathrm{GmbH}$.) as well as T. Ronge for helping with the measurements and maintaining the instrument. Thanks to the BADC for the calculation of trajectories and access to data of the European Center for Medium-range Weather Forecast (ECMWF).

\section{References}

Alpert, P., Kaufman, Y., Shay-el, Y., Tanré, D., Silva, A., Schubert, S., and Joseph, J. H.: Quantification of dust-forced heating of the lower tropophere, Nature, 395, 367-370, 1998.

Ansmann, A., Riesbel, M., and Weitkamp, C.: Measurement of aerosol extinction profiles with a raman lidar, Opt. Lett, 15, 746748, 1990.

Ansmann, A., Wandinger, U., Riesbel, M., Weitkamp, C., and Michaelis, W.: Independent measurement of extinction and backscatter profiles in cirrus clouds by using a combined raman elastic-backscatter lidar, Appl. Opt., 31, 7113-7131, 1992.

Barnaba, F. and Gobbi, G.P., Lidar estimation of tropospheric aerosol extinction, surface area and volume: Maritime and desert-dust cases, J. Geophys. Res., 106, 3005, 10.1029/2000JD900492, 2001.

Beyerle, G., Schäfer, H.-J., Neuber, R., Schrems, O., and McDermid, I.: Dual wavelength lidar observations of tropical highaltitude cirrus clouds during the ALBATROSS 1996 campaign, Geophys. Res. Lett., 25, 919-922, 1998.

Biele, J., Beyerle, G., and Baumgarten, G., Polarization lidar: correction of instrumental effects, Opt. Expr., 7, 427-435, 2000.

Colarco, P., Toon, O., Torres, O., and Rasch, P.: Determining the UV imaginary index of refraction of the saharan dust particles from total ozone mapping spectrometer data using a threedimensional model of dust transport, J. Geophys. Res., 107, AAC 4-1 to AAC 4-1 to 18, 10.1029/2001JD000903, 2002.

D’Almeida, G. A., Koepke, P., and Shettle, E.P., Atmospheric Aerosols : global climatology and radiative characteristics, DEEPAK, 1991.

Dubovik, O., Holben, B., Eck, T., Smirnov, A., Kaufmann, Y., King, M., Tanre, D., and Slutsker, I.: Variability of absorption and optical properties of key aerosol types observed in worldwide locations., J. Atmos. Sci., 59, 590-608, 2002.

Ferrare, R.A., Turner, D.D., Brasseur, L.H., Feltz, W.F., and T.P. Dubovik O, T.: Raman lidar measurements of the aerosol extinction-to-backscatter ratio over the southern great plains, J. Geophys. Res., 106, 20 333-20 344, 2001.

Griffin, D. W., Garrison, V.H., Herman, J., and Shinn, E.: African desert dust in the caribbean atmosphere: Microbiology and public health, AEROBIOLOGIA , 17(3), 203-213, 2001.

Hanisch, F. and Crowley, J. N.: Ozone decomposition on Saharan dust: An experimental investigation, Atmos. Chem. Phys. Discuss., 2, 1809-1845, 2002.

Herman, J. R., Bhartia, P. K., Torres, O., Hsu, C., Seftor, C., and Celarier, E.: Global distributions of UV-absorbing aerosols from Nimbus 7 TOMS data, J. Geophys. Res., 102, 16911-16922, 1997.

Holben, B. N., Tanré, D., Smirnov, A., Eck, T. F., Slutsker, I., Abuhassan, N., Newcomb, W. W. S. J. S., Chatenet, B., Lavenu, F., Kaufmann, Y., Castle, J., Setzer, A., Markham, B., Clark, D., Frouin, R., Halthore, R., Karneli, A., O’Neill, N., Pietras, C., Pinker, R., Voss, K., and Zibordi, G.: An emerging ground-based 
aerosol climatology: Aerosol optical depth from AERONET, J. Geophys. Res., 106, 12 067-12 098, 2001.

Hsu, N. C., Herman, J. R., and Weaver, C.: Determination of radiative forcing of Saharan dust using combined TOMS and ERBE data, J. Geophys. Res., 105, 20 649-20 662, 2000.

Husar, R. B., Prospero, J. M., and Stowe, L. L.: Characterization of tropospheric aerosols over the oceans with the noaa advanced very high resolution radiometer optical thickness operational product, J. Geophys. Res., 102, 16 889-16909, 1997.

Immler, F. and Schrems, O.: Lidar measurements of cirrus clouds in the northern and southern hemisphere during INCA $\left(55^{\circ} \mathrm{n}\right.$, $53^{\circ} \mathrm{s}$ ): A comparative study, Geophys. Res. Lett., 29, 56-1 to 56-4, 10.1029/2002GL015077, 2002.

Immler, F. and Schrems, O.: Determination of tropical cirrus properties by simultanious lidar and radiosonde measurements, Geophys. Res. Lett., 29, 5-1 to 5-4, 10.1029/2002GL015076, $2002 \mathrm{~b}$.

IPCC: Climate Change 2001, Cambridge University Press, 2001.

Klett, J.: Lidar inversion with variable backscatter/extinction ratios, Appl. Opt., 24, 1638-1643, 1985.

Mattis, I., Ansmann, A., Müller, D., Wandinger, U., and Althausen, D.: Dual-wavelength raman lidar observations of the extinctionto-backscatter ratio of Saharan dust, Geophys. Res. Lett., 29, 201 to 20-4, 10.1029/2001GL014271, 2002.

Melfi, S.: Remote measurements of the atmosphere using raman scattering, Appl. Opt., 11, 1605-1610, 1972.

Menzies, R., Tratt, D., Spinhirne, J., and Hlavka, D.: Aerosol layers over the Pacific Ocean: Vertical distributions and optical properties as observed by multiwavelength airborne lidars, J. Geophys. Res., 107, AAC 5-1 to 5-16, 10.1029/2001JD001196, 2002.
Mie, G.: Beiträge zur Optik trüber Medien, speziell kolloidaler Lösungen, Ann. Physik, 4, 377-445, 1908.

Mishchenko, M.I., Travis, L.D., Kahn, R. A., and West, R. A.: Modeling phase functions for dustlike tropospheric aerosols using a shape mixture of randomly oriented polydisperse spheroids, J. Geophys. Res., 102, 16 831-16847, 1997.

Prospero, J., Glaccum, R., and Nees, R.: Atmospheric transport of soil dust from Africa to South America, Nature, 289, 681-683, 1996.

Sasano, Y. and Browell, E.: Light scattering chracteristics of varoius aerosol types derived from multiple wavelength lidar observations., Appl. Opt., 28, 1670-1674, 1989.

Shinn, E. A.: African dust and the demise of caribbean coral reefs, Geophys. Res. Lett., 27, 3029-3032, 2000.

Sokolik, I. and Toon, O. B.: Direct radiative forcing by anthropogenic airborne mineral aerosols, Nature, 381, 681-683, 1996.

Sokolik, I. N. and Toon, O. B.: Incorporation of mineralogical composition into models of the radiative properties of mineral aerosol from UV to IR wavelengths, J. Geophys. Res., 104, 9423-9444, 1998JD200048, 1999.

Tegen, I., Lacis, A., and Fung, I.: The influence on climate forcing of mineral aerosols from disturbed soils, Nature, 381, 419-422, 1996.

Zhang, Y., Sunwoo, Y., Kotamarthi, V., and Carmichael, G. R.: Photochemical oxidant processes in the presence of dust: An evaluation of the impact of dust on particulate nitrate and ozone formation, J. Appl. Meteor., 33, 813-824, 1994. 